\title{
The Impact of Regional Industrial Structure Upgrading on the Economic Growth of Marine Fisheries in China-The Perspective of Industrial Structure Advancement and Rationalization
}

\author{
Bo Wang 1,2,3, Limin Han ${ }^{3,4}$ and Hongzhi Zhang ${ }^{5 *}$ \\ ${ }^{1}$ School of Economics and Management, Yantai University, Yantai, China, ${ }^{2}$ Fourth Institute of Oceanography, Ministry \\ of Natural Resources, Beihai, China, ${ }^{3}$ Institute of Marine Development, Ocean University of China, Qingdao, China, \\ ${ }^{4}$ Management College, Ocean University of China, Qingdao, China, ${ }^{5}$ Shandong Foreign Trade Vocational College, Qingdao, \\ China
}

OPEN ACCESS

Edited by:

Huang Wei,

Second Institute of Oceanography,

Ministry of Natural Resources, China

Reviewed by:

Liang Cao,

Institute of Oceanology (CAS), China

Yue Dongdong,

East China Sea Fisheries Research Institute (CAFS), China

*Correspondence:

Hongzhi Zhang

ouqdsnow@163.com

Specialty section This article was submitted to Marine Fisheries, Aquaculture and Living Resources, a section of the journal Frontiers in Marine Science

Received: 12 April 2021 Accepted: 14 June 2021

Published: 16 July 2021

Citation:

Wang $B$, Han $L$ and Zhang $H$

(2021) The Impact of Regional Industrial Structure Upgrading on

the Economic Growth of Marine Fisheries in China - The Perspective of Industrial Structure Advancement and Rationalization.

Front. Mar. Sci. 8:693804. doi: 10.3389/fmars.2021.693804
From the perspective of industrial structure advancement and rationalization, this paper studied the impact of regional industrial structure upgrading on the economic growth of marine fisheries through theoretical analysis and empirical tests. The results show the effects of different industrial structure upgrading on the economic growth of marine fisheries is varied. The advancement evolution has a "suppression effect," while rationalization evolution has a "promotion effect." The adverse impact of advancement evolution is greater than the favorable impact of rationalization evolution. Therefore, the development of marine fisheries reduces this unfavorable impact from advancement evolution by accelerating the transformation of innovation-driven internal combustion and creating new kinetic energy and fostering new business forms; it is also necessary to coordinate regional structure upgrading and industrial internal structure adjustment, promote the effect of structural rationalization, strengthen internal and external linkages, and improve the overall effectiveness of marine fisheries.

Keywords: regional industrial structure upgrading, marine fishery, economic growth, suppression effect, promotion effect

\section{INTRODUCTION}

Recently, China has implemented a supply-side structural reform aimed at adjusting the economic structure, optimizing the allocation of resource, and improving the quality and quantity of economic growth. The industrial structure is an important content of the supply-side structural reform. Throughout the industrial development history, the industrial focus has been characterized by the shift from low value-added industries to high value-added industries. The Chinese economy has already realized the transfer process from agriculture to industry or service industry. Therefore, the proportion of fishery in the national industrial system decreased from $5.28 \%$ in 2001 to $2.99 \%$ in $2017^{1}$. In new reform, industrial structure evolution is bound to have an effect on the sustainable

\footnotetext{
${ }^{1}$ Data obtained according to "China Fisheries Statistical Yearbook."
} 
development of marine fisheries economy in China. At present, industrial structure evolution mainly has two trends of advancement and rationalization. The former may promote capital and labor factors in the region to high-productivity or high-value-added sectors and guide the internal resources of marine fisheries to the non-fishing industry. It has a "siphon effect" for the low-productivity or low-value-added marine fisheries. The latter possibly drives technology, talents, and other factors to return to marine fisheries, which have a certain "return effect" for marine fisheries.

About the impact of industrial structure on economic growth, the theoretical research is common forming a series of theoretical research results. In the early days, Clark, Kuznets, Chenery, and Denison verified the relationship between industrial structure and economic growth by empirical analysis and formed the PettyClark's Theorem, Hoffman's Theorem, Kuznitz Department Structure Change Theory, and Channer's Standard Structure Model. They constituted a relatively systematic industrial structure theory. At present, most scholars (Jiang and Zhou, 2002; Bosworth and Collins, 2008; Wang and Qian, 2010; Ahmad et al., 2015; Yang and Zhang, 2018) believe that industrial restructuring could promote national economic growth and improve economic development efficiency, with a significant "structural dividend effect." There are also studies that hold the opposite view. Fonfría and lvarez (2005); Gao and Li (2006), Gan and Zheng (2009); Fassio (2010), and Xiaojing (2013) believe that industrial restructuring has certain constraints on economic growth and is inconducive to economic development. The possible factors for this result are resource mismatch, industrial inconsistency, etc. There are multiple dimensions to measure industrial structure indicators. Some studies further test their impact on economic growth from advancement and rationalization of industrial structure. Xie et al. (2019) and Shi (2020) believed that the advancement of industrial structure had a negative impact on marine economic growth and hindered marine economic development. On the contrary, the rationalization of the marine industry structure had a positive impact on the growth of the marine economy and promoted its development. At the same time, some people think that the impact of industrial structure on economic growth is non-linear and that there is a turning point. In addition, the negative impact of industrial structure advancement on coastal economic growth depends on the degree of industrial structure rationalization, showing a negative correlation.

Most of the research about the impact of industrial structure upgrading on marine fisheries economy (Lei, 2009; Bo et al., 2019) is only deductive from the theoretical level and lack objective quantitative research. Also, previous literatures indicate that most of the research mainly analyze the impact of industrial structure upgrading on economy from a total perspective or an internal perspective of the industry itself but lacking the research on the impact of macro-industry structural upgrading on specific industry development. Therefore, to promote the development of the marine fisheries economy in China, this paper considered regional industrial structure upgrading as an external environmental factor and analyzed the impact of regional industrial structure upgrading on marine fishery economy from the perspective of advancement and rationalization.

\section{THEORETICAL ANALYSIS}

\section{The Advancement of Regional Industrial Structure Causes the Flow and Redistribution of Resource}

In theory, it is believed that the outflow of marine fishery resources can cause the shortage of resources within the fishery, which restricts the economic development of marine fishery.

\section{The "Double Dilemma" of the Marine Fishery Labor Force}

The fishery labor force, who gradually masters the fishery operating skills based on years of work practice, has a strong occupational restraint. The development of fishery mechanization has released a large amount of labor. However, because fishermen rarely have other industrial skills, it is difficult for them to move quickly from marine fisheries to other industries. For example, there is no comparative advantage between the construction industry that relies purely on physical strength and the marine fishery. It is difficult to attract fishermen to turn to this industry. As a result, most of the fishery labor force is engaged in marine fishery, and a large number of surplus fishery labor has become the first dilemma. At the same time, along with the development trend of mechanization and intelligence, the demand for high-level fishery talents in marine fisheries has increased. However, nowadays, a large number of high-level talent are concentrated in the non-fishing industry with high productivity or growth rate, which leads to sufficient supply of high-end technical talents in marine fisheries. This is the second dilemma that constrains the economic growth of marine fisheries.

\section{Contradictions Escalated Between the High Capital Dependence of Fisheries and the Structural Outflow of Capital}

Marine fisheries are different from land agriculture. Its production activities are highly dependent on high-level tools (such as fishing boats, fishing gear, deep-water cages, etc.). The investment of this fishery equipment is much higher than that of land agriculture, and the capital recovery period is longer and the risk is greater. However, without these mechanical inputs, it is difficult for marine fisheries to conduct work. Simultaneously, with the decline of offshore fishery resources in China, the intensification of sea pollution, and fierce industrial competition in using marine space, marine fisheries are forced to develop deep sea fisheries. Deep sea aquaculture and oceanic and transoceanic fisheries have become the main industries for marine fishery space expansion. These industries are more dependent on highend equipment, such as the renovation of old fishing boats, the purchase of large fishing boats, which require substantial funding support. Therefore, in the long-term perspective, the capital demand in fisheries is constantly increasing. This is contrary to the advancement of regional industrial structure, which attracts fishery capital to flow the non-fishing industry. This has intensified the contradiction between the mismatch between 
supply and demand of marine fishery capital, to some extent, and affects the sustainable development of marine fisheries.

\section{The Rationalization of Regional Industrial Structure Promotes the Growth of Marine Fisheries by Balancing Economic Development}

The advancement of regional industrial structure has accelerated the inflow of marine fishery production factors (especially technology, talents, etc.) into the industrial sector with high productivity or growth rate and promoted the high-end development of the regional economy, but it has a certain impact on the development of the marine fishery economy. When the economy develops to a certain stage, regional development pays more attention to equilibrium, pursuing the rationalization of industrial structure. While ensuring the development of new leading industries, the rationalization of industrial structure gradually optimizes the resource allocation structure and promotes the coordinated and balanced development of regional industries. It brings "return effect" to the development of fisheries, which is reflected in promoting some resources such as science and technology, talents and information to spread to the marine fishery economic system, improving the scientific and technological level of marine fisheries, and total factor productivity. To a certain extent, this will eliminate the adverse effects of advancement evolution on the economic growth of marine fisheries.

\section{EXPERIMENTAL DESIGN AND ESTIMATION}

\section{Design of Experimental Model}

This paper establishes a model for the impact of regional industrial structure upgrading on the economic growth of marine fisheries by the VES production function. The specific form of the VES production function is shown in Eq. (1). On the basis of Eq. (1), the external factor regional industrial structure (RMFS) is introduced, and the formula is obtained by taking the logarithm of both sides of Eq. (2).

$$
\begin{aligned}
Y & =f(K, L)=A \bullet K^{\frac{\rho}{1+a}} \bullet\left[L+\left(\frac{b}{1+a}\right) \bullet K\right]^{\frac{a \rho}{1+a}} \\
\ln Y= & \ln A+\frac{\rho}{1+a} \ln K+\frac{a \rho}{1+a} \ln \left(L+\left(\frac{b}{1+a}\right) \bullet K\right) \\
& +\delta \ln \text { RMFS }
\end{aligned}
$$

In the formula, $K$ and $L$, respectively represent capital and labor force input, $A$ represents technological progress, $a$ and $b$ are exogenous parameters, and $\rho$ represents the coefficient of scale return. For $\ln (L+(b /(1+a)) \cdot K)=\ln (L+\lambda K)=F(\lambda)$ in Eq. (2), the expansion is performed according to the Taylor series at $\lambda=0, b=0, F(\lambda)=L+(K / L) \lambda+0(\lambda)$ can be obtained, and it can be simplified by substituting it into Eq. (2), and Eq. (3) can be obtained:

$$
\begin{aligned}
\ln Y= & \ln A+\frac{\rho}{1+a} \ln K+\frac{a \rho}{1+a} \ln L+\frac{a \rho b}{(1+a)^{2}} \frac{K}{L} \\
& +\delta \ln R M F S
\end{aligned}
$$

In Eq. (3), let $\beta_{0}=\ln \mathrm{A}, \beta_{1}=\rho /(1+a), \beta_{2}=(\mathrm{a} \rho) /(1+a)$, $\beta_{3}=(a \rho b) /(1+a)^{2}$, and $\beta_{4}=\delta$, and introduce the individual heterogeneity intercept term $\left(u_{i}\right)$ and the disturbance term $\left(\varepsilon_{i t}\right)$ that changes with the individual and time, establish a model for the impact of regional industrial structure upgrading on the economic growth of marine fisheries (4):

$$
\begin{aligned}
\ln g f p_{i, t}= & \beta_{0}+\beta_{1} \ln m f \text { capital }_{i, t}+\beta_{2} \ln {\text { f } \text { labor }_{i, t}} \\
& +\beta_{3} \frac{m f \text { capital }_{i, t}}{\text { flabor }_{i, t}}+\beta_{4} \text { RMFS }_{i, t}+\mu_{i t}+\varepsilon_{i}
\end{aligned}
$$

Among them, $\beta_{j}(j=1,2,3,4)$ represents the impact coefficient of marine fishery capital, marine fishery labor, marine fishery capital labor ratio, regional industrial structure on marine fishery economic growth, and $g f p_{i, t}$ is the total production value of marine fishery in $t$-year and $i$ region. fcapital $_{i, t}$ and $f$ labor $_{i, t}$ represent the marine fishery capital and labor force input level in $t$-year and $i$-region, respectively. $R M F S_{i, t}$ indicates the regional industrial structure level in $t$-year and $i$-region, and it contains the advancement and rationalization of industrial structure, which is $\mathrm{TH}_{i, t}$ and $\mathrm{TL}_{i, t}$. So, $R M F S_{i, t}=\left\{\mathrm{TH}_{i, t} T L_{i, t}\right\}$.

At the same time, considering factors affecting the economic growth of marine fisheries, in addition to industrial structure, labor, capital, it also includes other factors such as the degree of openness, policies, infrastructure, etc. In order to improve the accuracy of the model regression, control variables need to be introduced in the model. In order to avoid the randomness and one-sidedness of selecting control variables, this paper uses the interaction between the interpreted variables and the core explanatory variables as control variables to transform the model into:

$$
\begin{aligned}
\ln g f p_{i, t}= & \beta_{0}+\beta_{1} \ln m f \text { capital }_{i, t}+\beta_{2} \ln {\text { f } \text { labor }_{i, t}} \\
& +\beta_{3} \frac{m f \text { capital }_{i, t}}{\text { flabor }_{i, t}}+\beta_{4} \text { RMFS }_{i, t} \\
& +\alpha\left(\text { RMFS }_{i, t} \bullet \ln g f p_{i, t}\right)+\mu_{i}+\varepsilon_{i t}
\end{aligned}
$$

Considering that economic development is a dynamic process, this paper introduces the lag phase of the explained variable $\ln g f p_{i, t-1}$ into model (5) and constructs a dynamic regression model (6):

$$
\begin{aligned}
\ln g f p_{i, t}= & \eta \ln g f p_{i, t-1}+\beta_{1} \ln m f \text { capital }_{i, t}+\beta_{2} \ln \text { flabor }_{i, t} \\
& +\beta_{3} \frac{m f \text { capital }_{i, t}}{\text { flabor }_{i, t}}+\beta_{4} \text { RMFS }_{i, t} \\
& +\alpha\left(\text { RMFS }_{i, t} \bullet \ln g f p_{i, t}\right)+\varepsilon_{i t}+\mu_{i}
\end{aligned}
$$

To avoid possible endogenous problems and correlation problems in model estimation, this paper learned the practice of Chunhui et al. (2011) and introduced the explanatory variable 
lag and difference terms as instrumental variables. To this end, the method used in this paper is the dynamic panel generalized moment estimation method (GMM), and the overidentification test of instrumental variables is carried out through the Sargan test.

\section{Variable Settings and Data Explanation}

The variables mainly include economic growth of marine fisheries, labor force and capital of marine fisheries, and regional industrial structure.

(1) Explanatory variables: economic output of marine fisheries, measured objectively by the total economic output value of marine fisheries.

(2) Key explanatory variables: regional industrial structure (RMFS), which is measured by the advancement and rationalization of regional industrial structure.

(1) The advancement of regional industrial structure (TH). Referring to the measurement method of Linghui (2010), the Moore index is used to measure the advancement of regional industrial structure. Firstly, all industries are divided into three categories according to the standard of three industries, and the vector $X_{0}=\left(\begin{array}{lll}x_{1,0} & x_{2,0} & x_{3,0}\end{array}\right)$ is constructed by taking the contribution of the three industries to GDP as the component; secondly, Using $\mathrm{X}_{1}=\left(\begin{array}{lll}1 & 0 & 0\end{array}\right)^{T}, \mathrm{X}_{2}=\left(\begin{array}{lll}0 & 1 & 0\end{array}\right)^{T}, \mathrm{X}_{3}=\left(\begin{array}{lll}0 & 0 & 1\end{array}\right)^{T}$ to represent the vector of industries from low level to high level, and the angles $a_{j}(j=1,2,3)$ between $X_{0}$ and $X_{1}, X_{2}, X_{3}$ were calculated separately. The calculation formula is as follows:

$$
\alpha_{j}=\arccos \left(\sum_{i=1}^{3}\left(x_{i, j} \times x_{i, 0}\right) / \sqrt{\sum_{i=1}^{3} x_{i, j}^{2} \times \sum_{i=1}^{3} x_{i, 0}^{2}}\right)
$$

According to formula (7), the vector angle is calculated, and the angle between the proportion vector of the three industries and the corresponding coordinate axis is used to reflect and define the advanced value of industrial structure. The specific formula is as follows:

$$
T H_{i, j}=\sum_{i=1}^{3} \sum_{j=1}^{i} \alpha_{j}
$$

The greater the $T H_{i, j}$ is, the higher the level of industrial structure is.

(2) The rationalization of regional industrial structure (TL). Referring to the practice of Gan and Zheng (2009), the revised Taier index is used to measure the rationalization of regional industrial structure.

$$
T L_{t}^{j}=\sum_{i=1}^{3}\left(\frac{y_{i, t}^{j}}{y_{t}^{j}}\right)\left|\ln \left(\frac{y_{i, t}^{j} / y_{t}^{j}}{L_{i, t}^{j} / L_{t}^{j}}\right)\right|
$$

In formula (9), $t$ represents the period, $T L_{t}^{j}$ represents the degree of rationalization of the industrial structure of region $j, y_{i, t}^{j}$ represents the output value of the $i$ industry in the $j$ region, $y_{t}^{j}$ represents the sum of all industrial output values in the $j$ region, $L_{i, t}^{j}$ represents the labor input of the $i$ industry development in the $j$ region, and $L_{t}^{j}$ represents the total labor input for the development of all industries in $j$ region. When the economic development is in equilibrium, that is, $y_{i, t}^{j} / L_{i, t}^{j}=$ $y_{t}^{j} / L_{t}^{j}, T L_{t}^{j}$ is equal to 0 , indicating that the industrial structure is at an absolutely rational level. The larger the $T L_{t}^{j}$ is, the more unreasonable the industrial structure is.

(3) Intermediate variables: marine fishery labor force and capital. Among them, the marine fishery labor force is measured by the number of marine fisheries employees, reflecting the interannual change of labor input; marine fisheries capital is measured by the stock of fixed assets in marine fisheries. First, we used the fixed assets input of agriculture, forestry, animal husbandry, and fishery multiplied by the proportion of marine fishery to the total output value to indirectly measure the level of fixed assets investment in marine fisheries. Secondly, using the method of Bo et al. (2019), we measured the stock of fixed assets in marine fisheries.

Based on the availability of data and the uniformity of statistical caliber, we selected data on marine fisheries and regional economic development in 10 coastal areas (including Tianjin, Hebei, Liaoning, Jiangsu, Zhejiang, Fujian, Shandong, Guangdong, Guangxi, and Hainan) from 2003 to 2016 as a research sample. In order to improve the measurement accuracy and comparability, relevant economic output data are scaled down by the corresponding index in 2002 to eliminate the impact of inflation on economic development. The data are from "the China Fishery Statistical Yearbook," (Fisheries and Fisheries Administration of the Ministry of Agriculture, 2017) "the China Rural Statistical Yearbook," (Department of Rural Social Economic Investigation and National Bureau of Statistics, 2017) "the China Statistical Yearbook," (National Bureau of Statistics, 2017) and the statistical yearbooks in various coastal regions.

\section{Model Estimation}

We conducted a stability test on the economic output of marine fisheries, the marine fishery labor force, the marine fishery capital, and the advancement and rationalization of regional industrial structure by the Fisher-ADF test with different roots and the Levin-Lin-Chu (LLC) test method with the same root unit. The results showed that at the $5 \%$ level, $g f p_{i, t}$, flabor $_{i, t}, f_{\text {capital }}, t$, $T H_{i, t}$, and $T L_{i, t}$ and other variables passed the unit root test, indicating that the selected variables are stable.

First of all, we used the Hausman test to determine whether it is suitable for a random effect model or a fixed effect model. The results showed that "Prob > chi2" is 0.0001 , which was less than $5 \%$ of the significant level, so the fixed effect model was chosen. Secondly, this paper made a regression estimate of the static model. The regression results (Table 1) showed that the value of $R_{2}$ in model 1 was 0.998 , which indicated that the regression model fit the observations better, and the $F$ statistics value reached 161.17 , which passed $5 \%$ significance. The horizontal test indicated that the overall fit of the model is good. At the same time, based on the dynamic model estimation 
using GMM, the regression results (Table 1) showed that "Wald chi2" values in models $2-4$ had passed the $5 \%$ significance level test, indicating that the overall regression effect of models 24 was better. In terms of the validity test of the instrumental variables, the probability values of the $\operatorname{AR}(2)$ and Sargan tests were all greater than $5 \%$, indicating that the model estimates of the selected instrumental variables were valid.

From the regression coefficient of explanatory variables, the impact of regional industrial structure upgrading on the economic growth of marine fisheries is analyzed.

(1) Whether it is static regression analysis or dynamic regression analysis, $\mathrm{TH}$ and $\mathrm{TL}$ has passed the $5 \%$ significance level test, indicating that they have a significant impact on the economic growth of marine fisheries, but the mode of action is quite different. Although their influence factors are negative, they have different economic significance. $\mathrm{TH}$ restricts the growth of marine fisheries and brings "inhibition effect," while TL promotes the marine fisheries growth and produces a "promotional effect."

(2) Analysis of regression coefficients from interaction terms. At the $1 \%$ level of significance, the influence of the interaction between $\mathrm{TH}$ and the marine fisheries economy on the economic growth of marine fisheries has passed the test and is positively affected. This shows that the interaction promotes the economic growth of marine fisheries. However, $\left|\beta_{4} / \alpha\right|>1$, this shows that other factors besides $\mathrm{TH}$ is difficult to weaken the inhibitory effect of $\mathrm{TH}$. TH has become one of the main factors that inhibit the economic growth of marine fisheries. In models 3 and 4, the impact of the interaction between $\mathrm{TL}$ and other factors affecting marine fisheries economy on the economic growth of marine fisheries has passed the significant test of $10 \%$ and $5 \%$, and the influence coefficient is positive. This shows that the interaction term inhibits the economic growth of marine fisheries. However, $\left|\beta_{4} / \alpha\right|>1$, it shows that other factors besides TL are difficult to weaken this promotion effect of TL. Therefore, we conclude that rationalization of regional industrial structure is one of the main drivers of economic growth in marine fisheries.

(3) In addition, the results of model 4 show that the negative effect of $\mathrm{TH}$ is higher than the positive effect of TL. So, we can deduce that the rationalization of industrial structure is difficult to restrain the negative impact of the advancement of regional industrial structure in the current stage of China, reflecting that the overall effect of regional industrial structure upgrading on the economic growth of marine fisheries is negative.

\section{DISCUSSION}

\section{Inhibition Effect}

The main reason for the "inhibition effect" is the deterioration of the fishery internal resources due to the advancement of the regional industrial structure. Firstly, TH promotes the flow of production factors to high-productivity or high-growth sectors, that is, the fishery resources gradually flow to the secondary and tertiary industries of marine fisheries or non-fishing industries in Figure 1. Secondly, the mechanization and intelligent operation of marine fisheries gradually reduced the demand for traditional fishery labor. A large number of fishery laborers are released from marine aquaculture and fishing. The existence of surplus labor has become an important social problem facing the development

TABLE 1 | Model regression results of regional industrial structure upgrading affecting economic growth of marine fisheries ${ }^{a}$.

\begin{tabular}{|c|c|c|c|c|}
\hline Explanatory variables & Model 1 & Model 2 & Model 3 & Model 4 \\
\hline $\operatorname{lngfp}_{i, t-1}$ & - & $-0.025^{\star \star \star}(-3.58)$ & $0.824^{\star \star}(13.55)$ & $-0.023^{\star \star}(-2.10)$ \\
\hline Inflabor $_{i, t}$ & $-0.007(-1.11)$ & $0.023^{\star}(1.74)$ & $0.127^{\star \star}(2.22)$ & $0.016(1.57)$ \\
\hline Inmfcapital $i_{, t}$ & $0.013^{\star \star \star}(5.20)$ & $0.026^{\star}(1.94)$ & $0.005(0.16)$ & $0.030^{\star \star}(4.14)$ \\
\hline fclarr $_{i, t}$ & $0.0001(0.59)$ & $-0.0007(-0.98)$ & $0.002(1.13)$ & $0.001^{\star}(1.92)$ \\
\hline $\mathrm{TH}_{i, t}$ & $-0.801^{\star \star \star}(-35.99)$ & $-0.742^{\star \star \star}(-12.66)$ & - & $-0.817^{\star \star \star}(-7.46)$ \\
\hline $\mathrm{TH}_{i, t}{ }^{*} \operatorname{lngfp_{i,t}}$ & $0.151^{\star \star \star}(130.62)$ & $0.158^{\star \star \star}(31.24)$ & - & $0.152^{\star \star \star}(34.13)$ \\
\hline$T L_{i, t}$ & $-0.079^{\star \star}(-1.80)$ & - & $-1.553^{\star \star}(-2.03)$ & $-0.204^{\star *}(-2.33)$ \\
\hline$T L_{i, t}{ }^{*} \operatorname{lngfp} p_{i, t}$ & $0.010(1.36)$ & - & $0.285^{\star}(1.92)$ & $0.070^{\star \star}(2.24)$ \\
\hline _cons & $5.292^{\star \star \star}(36.92)$ & - & $0.579^{\star \star}(2.42)$ & - \\
\hline$R^{2}$ & 0.998 & - & - & - \\
\hline$F$ & $161.17^{\star \star \star}$ & - & - & - \\
\hline$A R(2)$ & - & 0.405 & 0.770 & 0.714 \\
\hline Sargan test ( $p$-value) & - & 0.583 & 0.213 & 0.550 \\
\hline Number of observations & 140 & 120 & 120 & 120 \\
\hline Methods & $F E$ & Diff-GMM & System-GMM & Diff-GMM \\
\hline
\end{tabular}

${ }^{*} 10 \%,{ }^{*} 5 \%$, and ${ }^{* * *} 1 \%$ - significant levels. values set in italics indicate $\mathrm{z} / \mathrm{t}$ values.

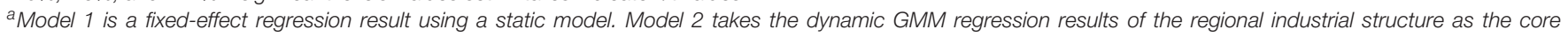

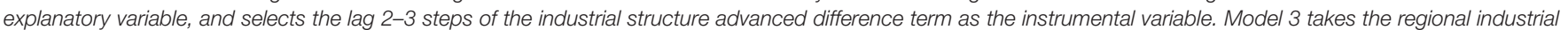

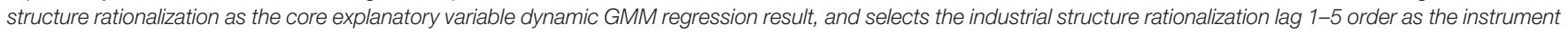

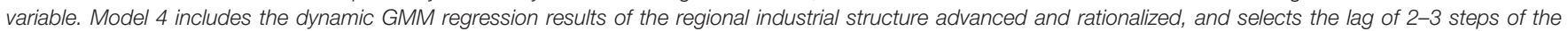
explanatory variables as the control variables. 
of marine fisheries. Although advancement of regional industrial structure evolution will promote traditional fishery labor to flow to other industries, the transfer efficiency of traditional fisheries labor is not high due to the development scale of fishery industry or service industry and the shift difficult of fishery labor to non-fishing industries.

At present, China's economy is in a period of transition from quantity development to quality improvement, and economic development is in the stage that production factor drive such as labor and capital transfers to technological innovation drive. Human capital and technology resources have become the key factors for achieving high-quality economic development. The transformational development of marine fisheries also needs to rely on the support of human capital and technological resources. However, TH promotes the flow of human capital and technological resources (including marine fisheries) to the secondary and tertiary industries in the regional economy, causing the slow development of marine fisheries due to the lack of high-level talents and technological resources. The economic losses caused by this lack are much higher than the economic benefits of simple labor transfer. In addition, the construction of "Ocean Powers" and the "Belt and Road Initiative" have attracted a large number of high-efficiency or high-growth blue industries to gather on the coast, occupying a large amount of sea space and restricting the economic development of marine fisheries. At the same time, it is greatly influenced by government decision-making preferences. The government generally prefers to invest in industries with high productivity or growth rates. As an inefficient industry, marine fisheries receive relatively few other support policies. Therefore, on the whole, it is believed that the advancement evolution of the regional industrial structure must inhibit economic development of marine fisheries.

\section{Promotional Effect}

The rationalization of regional industrial structure is an objective reflection of the rational allocation of production resources in various industries. It not only avoids the efficiency reduction

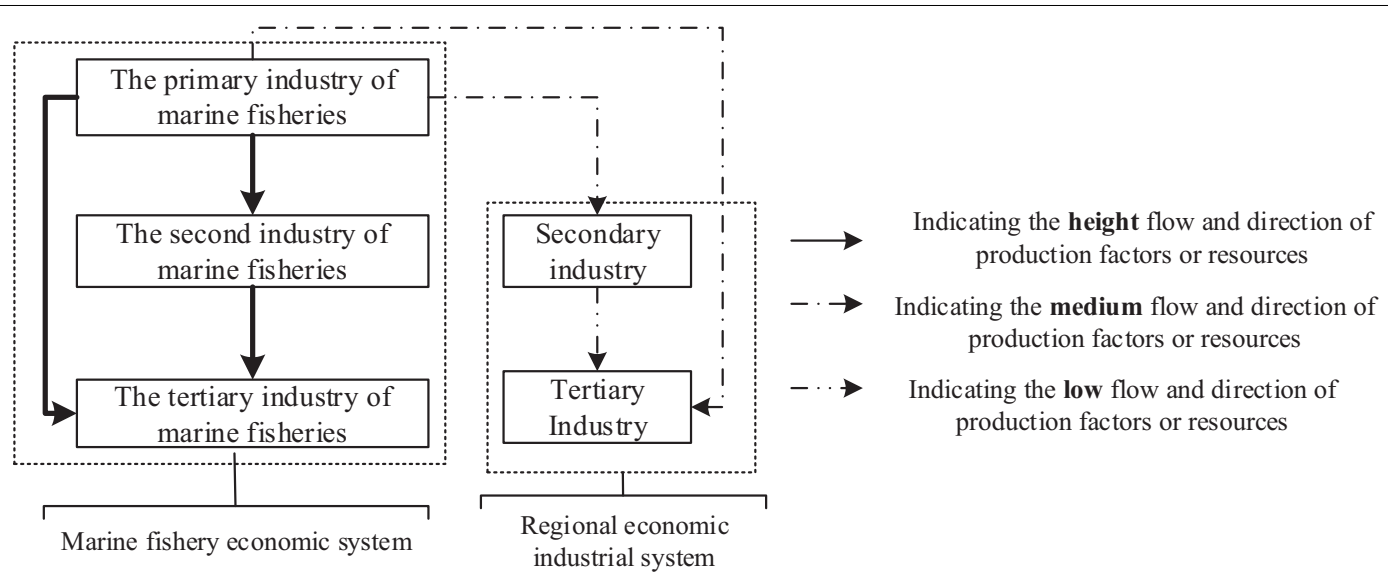

FIGURE 1 | The path of TH affects the economic growth of marine fisheries.

A

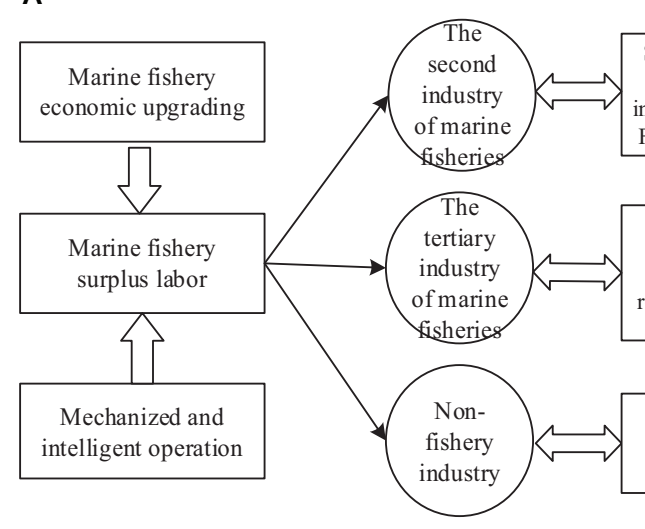

B
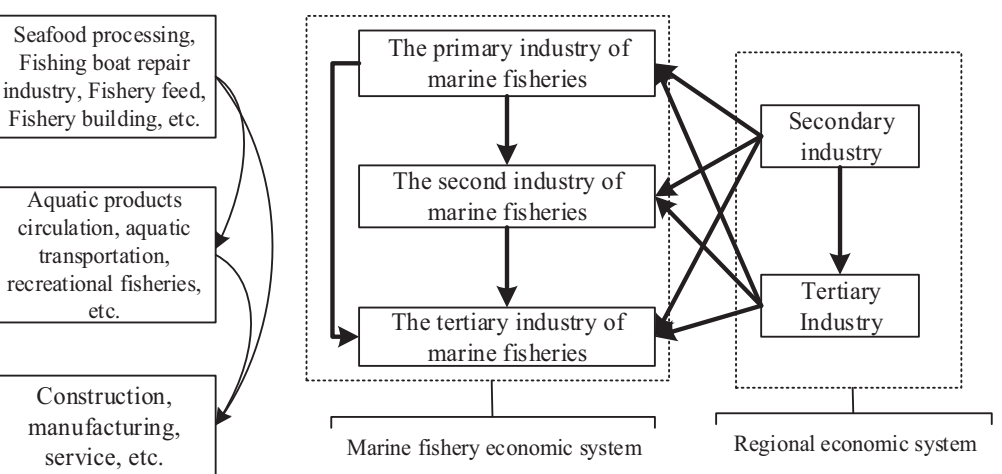

$\longrightarrow$ Indicating the flow of production factors such as capital and labor

FIGURE 2 | The path of TL affects the economic growth of marine fisheries. (A) Surplus labor flowed to other industries. (B) High-quality production factors returned to the fishery system. 
caused by the excessive agglomeration of production resources but also solves the weak economic development caused by the lack of production resources. Therefore, the rationalization of regional industrial structure has a promoting effect on industrial development. First, TL may promote the internal industrial structure rationalization of marine fisheries, transfer some surplus labor, promote the rational flow and allocation of fishery labor in the three industries, ease the dilemma of fishermen's conversion and transfer, and improve the efficiency of fishery labor. The specific action path of regional industrial structure rationalization is shown in Figure 2A.

Secondly, marine fisheries are high-tech-dependent industries, especially in marine fishery equipment such as fishing boat, breeding equipment, and fishing tools. However, TH has led to the lack of scientific and technological resources for marine fisheries, which has constrained its development. The empirical results prove that the evolution of regional industrial structure rationalization has eliminated this adverse effect to some extent. TL promotes the coordinated and balanced development of various industries by rationally arranging high-end resources such as education, science and technology, information, and Talents as shown in Figure 2B. It leads some high-end production resources to return to marine fisheries or through the diffusion and spillover of technology affects marine fishery economy, producing a positive "return effect" that drives the economic growth of marine fisheries. Although TL cannot completely eliminate the negative impact caused by the evolution of rationalization, we must also pay attention to its role in the process of economic development.

\section{CONCLUSION}

The research results show that the regional industrial structure upgrading has a significant impact on the economic growth of marine fisheries, but the different industrial structures have different characteristics, which are manifested in three aspects, as follows:

(1) The advancement of regional industrial structure has an adverse impact on the economic growth of marine fisheries and is called the "inhibition effect." The outflow of marine fishery resource has become the main guiding factor. At the same time, the lack of innovation power within the marine fishery and fierce competition in the use of marine space for industrial development have aggravated this negative effect.

(2) The rationalization of regional industrial structure has a significant "promoting effect" on the economic growth of marine fisheries. The "return effect" brought about by the rationalization evolution has guided some new elements and new resources into the marine fishery to a

\section{REFERENCES}

Ahmad, Z., Jun, M., and Khan, I. (2015). Agri. Industrial structure and its influence on energy efficiency: a study of pakistan. Eur. J. Econ. Stud. 11, 16-22. doi: 10.13187/es.2015.11.16 certain extent and promoted the innovative development of marine fishery economy. This is consistent with the results of theoretical analysis.

(3) The analysis of common effects reflects that the "promotion effect" brought about by the rationalization of regional industrial structure is lower than the inhibition effect brought about by the advancement evolution, which indicates that the impact of regional industrial structure upgrading on the economic growth of marine fisheries is unfavorable.

Therefore, under the background of industrial structure reform in China, we must pay attention to the following measures to achieve leapfrog development of marine fisheries. The first is to make use of the new resources and new elements, expanding the promotion effect of regional industrial structure rationalization. The second is to promote the transformation of new and old kinetic energy of marine fisheries, transforming the traditional structure of marine fishing and marine aquaculture, and transfer to develop the higher value-added industries, such as seafood processing industry, fisheries construction, fish feed and machinery, distribution services, and recreational fisheries. At the same time, it is necessary to cultivate and expand new forms of marine fishery. Third, we must coordinate regional industrial structure upgrading and internal adjustment of marine fisheries and improve the overall effect of structural adjustment through internal and external linkages and complementary advantages.

\section{DATA AVAILABILITY STATEMENT}

The original contributions presented in the study are included in the article/supplementary material, further inquiries can be directed to the corresponding author/s.

\section{AUTHOR CONTRIBUTIONS}

$\mathrm{LH}$ and $\mathrm{HZ}$ assisted BW with writing the manuscript. All authors contributed to the article and approved the submitted version.

\section{FUNDING}

This work was supported by the Guangxi Science and Technology Base and Talent Project (Guike AD20159004), Startup Project of Doctor scientific research of Yantai University (2220004/1103), the Youth Project of Natural Science Foundation of Guangxi Science and Technology Department (2018GXNSFBA050010), the Youth Project of National Social Science Foundation of China (19CJY023), and the Guangxi Key R \& D Plan (Guike AB1850023). 
Chunhui, G., Ruoguo, Z., and Dianfan, Y. (2011). The impact of China's industrial structure changes on economic growth and fluctuations. Econ. Res. 46, 4$16+31$.

Department of Rural Social Economic Investigation and National Bureau of Statistics (2017). China Rural Statistical Yearbook. Beijing: China Statistics Press.

Fassio, C. (2010). "CIS indicators and sectoral levels of production in Italy :1995-2006," in Proceedings of the DRUID-DME Academy Winter 2010 PhD Conference, Aalborg, 21-23.

Fisheries and Fisheries Administration of the Ministry of Agriculture (2017). 2017 China Fisheries Statistical Yearbook. Beijing: China Agriculture Press.

Fonfría, A., and lvarez, I. (2005). "Structural change and performance in spanish manufacturing: some evidence on the structural bonus hypothesis and explanatory factors," in Instituto Complutense de Estudios Internacionales Universidad Complutens de Madrid Working Paper, (Madrid: Complutense University of Madrid).

Gan, C., and Zheng, R. (2009). An empirical study on change of industrial structure and productivity growth since reform and opening-up-a test of "structuralbonus hypothesis" from 1978 to 2007 in China. China Indust. Econ. 2, 55-65.

Gao, G. H., and Li, X. J. (2006). Spatial analysis of the contribution of industrial structure change to regional economic growth: a case study of henan province. Econo. Geogr. 26, 270-273.

Jiang, Z., and Zhou, Y. (2002). The effect of industrial structure change in economic growth: China's empirical analysis and policy implications. Finance Econ. J.

Lei, S. (2009). Research on the Transformation of Fisheries Economic Growth Mode in China. Qingdao: Ocean University of China.

Linghui, F. (2010). An empirical research on industry structure and economic growth. Stat. Res. 27, 79-81.
National Bureau of Statistics (2017). China Statistical Yearbook. Beijing: China Statistics Press.

Shi, L. Y. (2020). Industrial structure changes, spatial spillover and economic growth in the yangtze river delta. J. Coastal Res. 107, 377-382. doi: 10.2112/ jcr-si107-086.1

Wang, M., and Qian, L. (2010). The effect of industrial structure changes on economic growth: an analysis based on input and output. J. Shijiazhuang Univ. Econ. 33, 16-19.

Xiaojing, Y. (2013). The industrial structure effect of China's economic growth during the transition period. Finance Econ. 7, 55-61.

Xie, B., Zhang, R., and Sun, S. (2019). Impacts of marine industrial structure changes on marine economic growth in China. J. Coastal Res. 98, 314-319. doi: $10.2112 /$ si98-075.1

Yang, Z., and Zhang, P. (2018). Financial structure, industrial structure and economic growth-_an empirical test based on the perspective of new structure finance. Economics 17, 847-872.

Conflict of Interest: The authors declare that the research was conducted in the absence of any commercial or financial relationships that could be construed as a potential conflict of interest.

Copyright (c) 2021 Wang, Han and Zhang. This is an open-access article distributed under the terms of the Creative Commons Attribution License (CC BY). The use, distribution or reproduction in other forums is permitted, provided the original author(s) and the copyright owner(s) are credited and that the original publication in this journal is cited, in accordance with accepted academic practice. No use, distribution or reproduction is permitted which does not comply with these terms. 